\title{
Anaemia in Pregnancy: Assessing the Role of Socio-demographic Factors
}

\author{
Mohamed Omar ${ }^{1}$, Ronnie Midigo², Isaac Okeyo ${ }^{1}$, Samuel Otieno ${ }^{1}$ \\ ${ }^{1}$ Great Lakes University of Kisumu, Kenya \\ ${ }^{2}$ University of Nairobi, Kenya
}

Correspondence to: Ronnie Midigo, University of Nairobi, Kenya; E-mail: ronniemidigo@gmail.com Received date: February 25, 2020; Accepted date: February 27, 2020; Published date: March 10, 2020

Citation: Omar M, Midigo R, Okeyo I, et al. (2020) Anaemia in Pregnancy: Assessing the Role of Socio-demographic. J Obst Gynecol Surg. 1(1): pp. 1-7. Copyright: (C) 2020 Omar M, et al. This is an open-access article distributed under the terms of the Creative Commons Attribution License, which permits unrestricted use, distribution and reproduction in any medium, provided the original author and source are credited.

\section{ABSTRACT}

In the world, more than half of pregnant women are anaemic. The burden of disease is heavy yet poorly estimated. Knowledge of the current situation in our environment is necessary. This knowledge will enhance early detection and timely management of anaemia in pregnancy. This was an analytical cross-sectional study that employed both qualitative and quantitative data collection methods. The aim of the study was to determine the socio-demographic factors associated with anaemia among women of reproductive age attending antenatal clinics in Garissa County Referral Hospital. Data were collected using structured questionnaires and the Key Informant Interview Guide by two research assistants. Validity and reliability were ensured by pre-testing the questionnaires. A total of $\mathbf{3 6 6}$ out of $\mathbf{3 8 4}$ expected women were interviewed. Six Key Informant Interviews were also conducted. The Nursing officer-in-charge of maternal and child health Clinic, as well as five nurses attending to the antenatal clinic, were interviewed. Data analysis was done using SPSS version 20. Results are presented in tables, graphs, and charts. Pearson's Correlation coefficient was applied to the linear relationship between variables. The prevalence of anaemia was found to be very high among the participants of the study (64\%). The study established that that education, religion, and the number of deliveries are significant predictive factors for anaemia $(P<0.05)$. The study recommends that the community through government agencies and non-governmental organization partners need to invest in educating the girl child beyond the primary level, special education campaigns on the nutritional requirements and the benefits of iron supplements issued at the health facilities targeting this group be developed and to empower women economically. Finally, the study recommends that the magnitude of the contribution of the various factors to the outcome variable being investigated. The direction of the relationship between the various factors and the outcome variable also to be investigated for this community.

\section{Keywords:}

Parity, Demographic factors, Anaemia, Pregnancy

\section{Introduction}

Anaemia in pregnancy is one of the most common preventable causes of maternal morbidity and poor prenatal outcome. Anaemia is defined as a decrease in the concentration of circulating red blood cells or in the haemoglobin concentration and a concomitant impaired capacity to transport oxygen because of a low level of circulating erythrocyte than the normal [1]. World Health Organization has accepted up to $11 \mathrm{gm}$ per cent as the normal haemoglobin level in pregnancy. Therefore, any haemoglobin level below $11 \mathrm{gm}$ in pregnancy should be considered as anaemia [2].

Iron deficiency anaemia (inadequate amount of red blood cells caused by lack of iron) is highly prevalent in less developed countries but also remains a problem in developed countries where other forms of malnutrition have already been virtually eliminated. Anaemia induces the most dramatic consequences, including increased risk of maternal morbidity and mortality, abortion, poor intrauterine growth, preterm birth and low birth weight [3]. These effects, in turn, result in higher perinatal morbidity and mortality, and higher infant mortality rate. The causes of anaemia include genetic factors, nutritional deficiencies, and infectious agents. Both haemoglobin and haematocrit (Packed Cell Volume) are measured through fresh whole blood and are dependent on plasma volume. Thus, factors such as dehydration as well as over hydration can affect the test results. In fact, haematocrit is a more precise parameter than haemoglobin to determine the ratio of erythrocyte volume to the total blood volume [4].

Several factors have been shown to be responsible for the high prevalence of anaemia in childbearing women, and these vary according to geographical location. It has been noted that during pregnancy there is an increased demand for nutrients as a result of the expanding maternal RBC mass and the needs of the growing foetus and placenta, and in between pregnancies the demands are increased by the iron loss due to menstruation [5]. In Africa, anaemia in women is caused by multiple factors including iron deficiency, malaria, folic acid deficiency, parasitic infections, Haemoglobinopathies and other nutritional deficiencies and infections [5].

Anaemia in pregnancy affects both the mother and the outcome of the pregnancy. It impairs cognitive development, reduced physical work capacity and in severe cases increased risk of mortality particularly during the prenatal period. Severe anaemia has been associated with maternal mortality, infant death and premature births. In Kenya and in specifically Garissa 
county, despite the support given by the Ministry of health and sanitation, anaemia in pregnancy seems to be still a significant problem. An understanding of the factors associated with the causes of anaemia could be necessary for informed control strategies. Further, the lack of well-documented studies on the prevalence of anaemia among women of reproductive age could be another challenge impeding effort towards addressing the problem of anaemia in pregnancy in Garissa County. With the availability of data on the prevalence of anaemia, interventions including the provision of iron supplements as well as proper nutrition can be put into place as a remedy.

\section{Methodology}

A descriptive cross-sectional approach was adopted as the study design. The study was carried out in Garissa County Referral Hospital. The estimated ANC population in a period of two months upon which the study was to be conducted was 7,000 . There is a Nursing officer managing the ANC clinic, and enough other nursing staff manning the clinic too, as well as a reliable laboratory back up. Garissa County Referral Hospital is the only level five Referral Centre for the Counties in North Eastern region as well as some neighbouring Counties in Eastern and Coast regions and has since received much attention from various developmental partners in an effort to expand its capacity. It has a total of 224-bed capacity and 9 Cots [6]. Women of reproductive age attend the hospital for maternal services including nutritional counselling. The population for

Table 1: Demographic characteristic of respondents.

\begin{tabular}{|c|c|c|c|}
\hline \multicolumn{2}{|l|}{ Variable } & \multirow{2}{*}{$\begin{array}{l}\text { Frequency } \\
238\end{array}$} & \multirow{2}{*}{$\frac{\text { Percent }}{65}$} \\
\hline Age in years & $18-22$ & & \\
\hline & $23-27$ & 89 & 24 \\
\hline & $28-32$ & 17 & 5 \\
\hline & $33-37$ & 18 & 5 \\
\hline & 38 and above & 4 & 1 \\
\hline \multirow[t]{4}{*}{ Highest level of education } & None & 264 & 72 \\
\hline & Primary & 77 & 21 \\
\hline & Secondary & 20 & 6 \\
\hline & Tertiary/college & 5 & 2 \\
\hline \multirow[t]{3}{*}{ Religion } & Muslim & 308 & 84 \\
\hline & Christian catholic & 28 & 8 \\
\hline & Christian protestant & 30 & 8 \\
\hline \multirow[t]{3}{*}{ Parity } & $<=3$ & 160 & 44 \\
\hline & $4-6$ & 86 & 23 \\
\hline & $>7$ & 121 & 33 \\
\hline \multirow[t]{4}{*}{ Present number of children } & $<=3$ children & 165 & 45 \\
\hline & 4-6 children & 121 & 33 \\
\hline & 7-9 children & 80 & 22 \\
\hline & & 366 & 100 \\
\hline
\end{tabular}

\section{Prevalence of anaemia}

The study sought from the participating mothers whether they had ever been diagnosed with anaemia. Of the 133 participating mothers, 209 (57\%) indicated that they had been diagnosed with anaemia. Figure 1 below represents the responses from this study comprised women of reproductive who are between 15-49 years of attending antenatal clinic. A total of 384 women were sampled using basic descriptive statistics (frequencies and percentages) and inferential statistics (Chi-square tests) are used to compare variables.

\section{Results}

\section{Demographic characteristics of the respondents}

Of the 366 mothers interviewed, 238 (65\%) were between the ages 18-22. Those who were aged between 23-27 years were 89 (24\%) while between 28-32 years old was 17 (5\%). A total of $18(5 \%)$ of the mothers were aged between $33-37$ years. Only ( $1 \%$ ) of the mothers were aged above 38 years. The study revealed that out of the 366 mothers sampled for the study, 264 (72\%) had no education. Only 77 (21\%) had primary school education. Further, a smaller number, 20 $(6 \%)$ and $5(2 \%)$ of the mothers had secondary and tertiary education respectively. A majority of the mothers, 165 (45\%) indicated that they had between 1-3 children by the time of the study. One hundred and twenty-one (33\%) had between 4-6 children while 80 (21\%) had 7-9 children. While most women were multiparous, a majority of 160 (44\%) had had between 1-3 pregnancies. Another 121 (33\%) indicated that they had been pregnant more than 7 times and more. Those who had delivered 4-6 times were 86 (23\%). Table 1 below represents the socio-demographic characteristics of the 333 mothers who participated in the study.

The study also sought from the participants who had indicated that they had ever been diagnosed with anaemia (209) to indicate which type of anaemia they were diagnosed with. A majority, 151 (72\%) indicated that they were diagnosed with 
diagnosed with severe anaemia. Figure 2 below represents the types of anaemia the participating mothers had.

The study also sought from the participants who had indicated that they had ever been diagnosed with anaemia (209) to indicate which type of anaemia they were diagnosed with. A majority, 151 (72\%) indicated that they were diagnosed with severe anaemia. Figure 2 below represents the types of anaemia

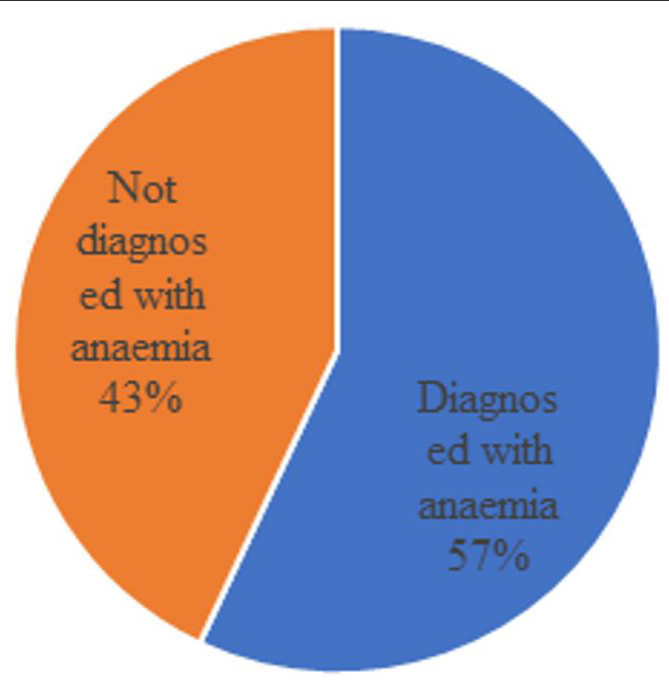

Figure 1: Prevalence of Anaemia

\section{Demographic characteristics associated with anaemia}

Age, parity, number of live births, present number of children, religion as well as the highest education attained were used in crosstabs with the place of delivery. Table 2 below represents the relationship between the demographic factors and the anaemia

Generally, a majority of the participants had anaemia. Of the 238 mothers of ages between $18-22$ years old, $135(57 \%)$ had been diagnosed with anaemia. Similarly, of the 89 mothers who were 23-27 years old, a majority, 59 (66\%) indicated that they had been diagnosed with anaemia. Age of the mother was found to be of statistically significant relationship with anaemia $(X 2=7.003, d f=4, p$ value $=0.03)$. The study also found that about

\section{the participating mothers had.}

In a Key Informant Interview, it emerged that the prevalence of anaemia was high in the region. A participant indicated that "Anaemia is one of the common nutritional diseases that affect most of the women who come to this clinic. You can even tell by looking at them that this has severe anaemia. Most women are like that" (KII, 2).

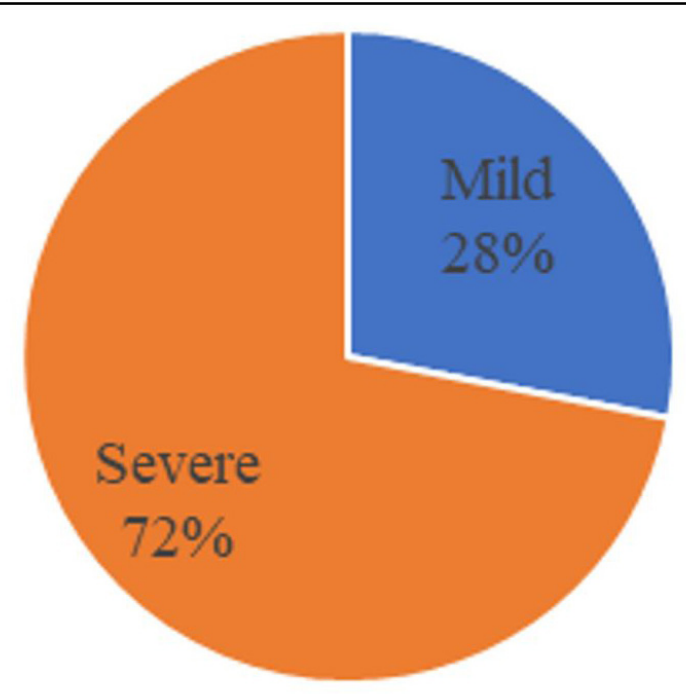

Figure 2: Type of Anaemia Diagnosed.

half of the women who participated in the study were para 3 or less. Of these (160), the ones who had anaemia were 72 (45.0\%). The $X^{2}$ value was found to be 17.39006 at a significance of 0.001 indicating a positive correlation. This means that as parity increased, the likelihood of having anaemia increased. Among all the respondents, the group that had 3 or less children were mostly negative for anaemia (60.8\%). It indicates that the lesser the number of children the lower the chance of being diagnosed with anaemia. $X^{2}=39.349, d f=2, p$ value $=0.001$. There was also a very strong positive correlation between the highest level of education as well as religion and anaemia indicating that as education increases, the less likely a mother will have anaemia and that those of the Islam religion/culture are likely to suffer from anaemia as shown in the Table 2 below.

Table 2: Demographic factors associated with Anaemia.

\begin{tabular}{|c|c|c|c|c|c|c|c|c|c|}
\hline \multicolumn{2}{|l|}{ Variables } & \multicolumn{5}{|c|}{ Have you ever been diagnosed with anaemia } & \multirow[t]{2}{*}{$\mathrm{X}^{2}$ value } & \multirow[t]{2}{*}{$d f$} & \multirow[t]{2}{*}{ Sig. } \\
\hline & & Yes & $\%$ & No & $\%$ & Total & & & \\
\hline \multirow[t]{5}{*}{ Respondents age group } & $18-22$ years & 135 & 56.76 & 104 & 43.24 & 238 & \multirow[t]{5}{*}{7.003} & \multirow[t]{5}{*}{4} & \multirow[t]{5}{*}{0.03} \\
\hline & $23-27$ years & 59 & 66.17 & 31 & 33.83 & 89 & & & \\
\hline & $28-32$ years & 6 & 33.96 & 10 & 66.04 & 17 & & & \\
\hline & 33-37 years & 8 & 44.9 & 9 & 55.1 & 18 & & & \\
\hline & $\begin{array}{l}38 \text { years and } \\
\text { above }\end{array}$ & 1 & 28.87 & 2 & 71.13 & 4 & & & \\
\hline \multirow[t]{3}{*}{ Parity } & $<=3$ & 72 & 45 & 87 & 55 & 160 & \multirow[t]{3}{*}{17.3901} & \multirow[t]{3}{*}{2} & \multirow[t]{3}{*}{0.001} \\
\hline & $4-6$ & 61 & 70.93 & 25 & 29.07 & 86 & & & \\
\hline & $>7$ & 76 & 62.81 & 45 & 37.19 & 121 & & & \\
\hline \multirow{3}{*}{$\begin{array}{l}\text { Present number of } \\
\text { children }\end{array}$} & $<=3$ children & 65 & 39.19 & 100 & 60.81 & 165 & \multirow[t]{3}{*}{39.349} & \multirow[t]{3}{*}{2} & \multirow[t]{3}{*}{0.001} \\
\hline & 4-6 children & 84 & 69.42 & 37 & 30.58 & 121 & & & \\
\hline & 7-9 children & 60 & 75.06 & 20 & 24.94 & 80 & & & \\
\hline
\end{tabular}




\begin{tabular}{|c|c|c|c|c|c|c|c|c|c|}
\hline \multirow{4}{*}{$\begin{array}{l}\text { Highest level of } \\
\text { education attained }\end{array}$} & None & 173 & 65.61 & 91 & 34.39 & 264 & \multirow[t]{4}{*}{34.8154} & \multirow[t]{4}{*}{3} & \multirow[t]{4}{*}{0.001} \\
\hline & Primary & 33 & 42.86 & 43 & 57.14 & 77 & & & \\
\hline & Secondary & 2 & 11.55 & 18 & 88.45 & 20 & & & \\
\hline & Tertiary/College & 0 & 0 & 5 & 100 & 5 & & & \\
\hline \multirow[t]{2}{*}{ Religion } & Christian & 15 & & 81 & & 96 & \multirow[t]{2}{*}{51.2588} & \multirow[t]{2}{*}{1} & \multirow[t]{2}{*}{0.001} \\
\hline & Muslim & 194 & & 76 & & 270 & & & \\
\hline
\end{tabular}

In a Key Informant Interview, it emerged that the age of women, level of education and the family size were some of the demographic factor related to anaemia. One of the informants indicated that "Anaemia is today mostly found among older women. I may also say that women of lower education standards (low levels of education) are also likely to suffer anaemia" (KII, 4).

Another stated that "Women who have larger family size are more likely to suffer from anaemia. You know children are valued in most families around here. So, tell me, if a woman has more children and there is a lack of food, wouldn't she go without food and let her children feed?" (KII, 7)

Further regression analysis was conducted to ascertain how demographic factors influence anaemia. Table 3 presents a summary of the output given below:

Table 3: Summary of regression analysis for demographic factors and anaemia.

\begin{tabular}{|l|l|}
\hline Regression Statistics \\
\hline Multiple R & 0.677067 \\
\hline R Square & 0.45842 \\
\hline Adjusted R Square & 0.422315 \\
\hline Standard Error & 45.02094 \\
\hline t Stat & 0.545097 \\
\hline Significance F & 0.002831 \\
\hline P-value & 0.5937 \\
\hline Observations & 17 \\
\hline
\end{tabular}

Table 4: Association between Cultural Factors and Anaemia.

\begin{tabular}{|c|c|c|c|c|c|c|c|c|c|}
\hline \multicolumn{10}{|c|}{ Have you been diagnosed with anaemia } \\
\hline \multicolumn{2}{|l|}{ Variables } & \multicolumn{2}{|l|}{ Yes } & \multicolumn{2}{|l|}{ No } & \multirow{2}{*}{\multicolumn{2}{|c|}{$\mathrm{X}^{2}$}} & \multirow[t]{2}{*}{ df } & \multirow[t]{2}{*}{ Sig. } \\
\hline & & f & $\%$ & $f$ & $\%$ & & & & \\
\hline \multirow{2}{*}{$\begin{array}{l}\text { Took iron tablets during } \\
\text { pregnancy }\end{array}$} & Yes & 80 & 34.33 & 153 & 65.67 & 233 & \multirow[t]{2}{*}{135.7} & \multirow[t]{2}{*}{1} & \multirow[t]{2}{*}{0.001} \\
\hline & No & 129 & 96.99 & 4 & 3.01 & 133 & & & \\
\hline \multirow{2}{*}{$\begin{array}{l}\text { diet change with your } \\
\text { pregnancy }\end{array}$} & Yes & 55 & 93.22 & 4 & 6.78 & 59 & \multirow[t]{2}{*}{35.29} & \multirow[t]{2}{*}{1} & \multirow[t]{2}{*}{0.001} \\
\hline & No & 154 & 51.51 & 145 & 48.49 & 299 & & & \\
\hline \multirow{2}{*}{$\begin{array}{l}\text { culture prohibit some } \\
\text { foods during pregnancy }\end{array}$} & Yes & 117 & 59.69 & 79 & 40.31 & 196 & \multirow[t]{2}{*}{1.29} & \multirow[t]{2}{*}{1} & \multirow[t]{2}{*}{0.52} \\
\hline & No & 92 & 53.8 & 79 & 46.2 & 171 & & & \\
\hline \multirow{2}{*}{$\begin{array}{l}\text { Religion prohibit some } \\
\text { foods during pregnancy }\end{array}$} & Yes & 142 & 60.68 & 92 & 39.32 & 234 & \multirow[t]{2}{*}{3.39} & \multirow[t]{2}{*}{1} & \multirow[t]{2}{*}{0.18} \\
\hline & No & 67 & 50.76 & 65 & 49.24 & 132 & & & \\
\hline \multirow[t]{3}{*}{ Religion } & Muslim & 204 & 66.23 & 104 & 33.77 & 308 & \multirow[t]{3}{*}{66.23} & \multirow[t]{3}{*}{2} & \multirow[t]{3}{*}{0.001} \\
\hline & Christian Catholic & 3 & 10.71 & 25 & 89.29 & 28 & & & \\
\hline & $\begin{array}{l}\text { Christian } \\
\text { Protestant }\end{array}$ & 2 & 6.67 & 28 & 93.33 & 30 & & & \\
\hline
\end{tabular}

As indicated in Table 3, Multiple $\mathrm{R}$ of 0.677067 indicates a positive relationship between the variables. This shows that demographic factors are indeed associated with anaemia among pregnant women in the study area. The coefficient of multiple determination for the regression equation ( $R$ Square $=0.45842$ ) reveals a $45.8 \%$ fit indicating that only $45.8 \%$ of the variables were catered for in the equation. The significant $F$ coefficient in the study was 0.002831 indicating a non-zero probability of no association. The regression analysis revealed an insignificant $p=0.5937$ with a t stat of 0.545097 for the intercept. The findings reveal an insignificant relationship between demographic factors and anaemia among pregnant women in the study area

\section{Cultural factors associated with anaemia}

The findings of the study reveal that of the 366 respondents, 129 (96.99\%) who did not take iron tablets during pregnancy had anaemia. Failure to take iron tablets during pregnancy was a statistically significant factor associated with anaemia $\left(X^{2}=135.7, p=0.001\right)$. Similarly, change of diet was significantly associated with anaemia. Among the women who did not change diet during pregnancy (299), 154 (51.51\%) had anaemia $\left(X^{2}=35.29, p=0.001\right)$. this implies that diet there were dietary restrictions in the area of the Study. Asked whether culture and religion prohibited some foods during pregnancy, 142 $(60.68 \%)$ of the women who indicated that their culture prohibited some foods during pregnancy were also positive for anaemia. However, the study did not find a significant statistical association between dietary restrictions by the culture and anaemia. Table 4 below represents the association between cultural factors and anaemia. 


\begin{tabular}{|l|l|c|c|c|c|c|c|c|c|}
\hline \multirow{2}{*}{ Ethnicity } & Somali & 206 & 62.8 & 122 & 37.2 & 328 & 41.91 & 1 & 0.001 \\
\cline { 2 - 11 } & Other & 3 & 7.89 & 35 & 92.11 & 38 & & & \\
\hline Total & & 209 & & 157 & & 366 & & \\
\hline
\end{tabular}

During the Key informant interviews, it emerged that culture influence dietary intake and thus anaemia.

Interviewer: "It seems most pregnant women suffer from anaemia in this are...does culture play a role in this?"

Respondent: "yes, I think largely in our community, it is the man who is given priority when it comes to food. As such, men would eat the liver and other parts...in some cases, traditional restrictions on diet would apply, a woman would be denied some foods which are rich in iron

Interviewer: "Why would this be so?"

Respondent: "They claim that such food would make the baby overgrow and the mother would die during delivery".

In order to ascertain the relationship between socio-cultural factors and anaemia in pregnancy, regression analysis was conducted. Table 5 below presents the findings.

Table 5: Summary of regression analysis on the relationship between sociocultural factors and anaemia in pregnancy.

\begin{tabular}{|l|l|}
\hline Regression Statistics & \\
\hline Multiple R & 0.598421 \\
\hline R Square & 0.358108 \\
\hline Adjusted R Square & 0.299754 \\
\hline Standard Error & 59.0227 \\
\hline Significance F & 0.030723 \\
\hline t Stat & 1.247406 \\
\hline P-value & 0.238152 \\
\hline Observations & 13 \\
\hline
\end{tabular}

The finding as shown in Table 5 above indicates a Multiple $\mathrm{R}$ of 0.598421 indicating a positive relationship between the variables. This shows that socio-cultural factors are indeed associated with anaemia among pregnant women in the study area. The coefficient of multiple determination for the regression equation ( $R$ Square $=0.358108$ ) indicates a mere 35.8 $\%$ fit to the equation. The $\mathrm{F}$ statistics and significant $\mathrm{F}$ produced in the analysis were 6.136834 and 0.030723 . This is to indicate that there was a non-zero probability of relationship in the equation. Table 4 above presents a summary of the findings. The findings reveal at-statistics of 1.247406. This was at an insignificant $p=0.238152$. The finding indicates not a direct relationship between the variables. Details on the test statistics are as provided in Table 5 above.

\section{Discussion}

\section{Prevalence of anaemia}

The study found the prevalence of anaemia among pregnant mothers attending antenatal clinic in Garissa County Referral Hospital to be $57 \%$ of which $72 \%$ were severe anaemia. The findings of this study indicate a lower anaemia incidence as compared to a study conducted in the former Garissa District which found out that about $88.1 \%$ of women of reproductive age screened had anaemia that a greater percentage of the women who were anaemic came from the rural regions within the area. While the present study did not segregate between the rural and urban, a study appearing indicates that the prevalence of maternal anaemia has been on the decline in Kenya since the year 1997 when it declined from $54 \%$ and was estimated to be about 36.00 as of the year 2011. According to the WHO report, the global prevalence of anaemia among pregnant women is $55.9 \%$. This global figure is slightly lower than that of the study area.

The findings of this study, therefore, confirm a decline in the prevalence of anaemia among women of reproductive age. In a Kenya anaemia data forecast 2020, prevalence of anaemia among women of reproductive age (\% of women ages 15-49) in Kenya was reported at $27.2 \%$ in 2016, following a declining trajectory since 2006 and with a slight increment in the year 2018 (“Kenya 2008-2018 Data | Forecast 2020"). However, the findings of this study further points to a higher prevalence of anaemia in Garissa County as compared to the national level of about 38\% [7].

\section{Demographic factors associated with anaemi}

The study identified a number of demographic factors associated with anaemia. The factors include the level of education of the mother, religion, number of children and live births. This finding indicates that most women had low levels of education, had larger parity and gravidity and are practising the Islamic religion attending antenatal clinic at Garissa Referral hospital are likely to be diagnosed with anaemia. The study finds that mothers who did not have any formal education were more likely to suffer from anaemia than those who had formal education. This indicates a trend that lower levels of education contribute to a high risk of anaemia. In a study done in India, it was shown that anaemia was more common among illiterate pregnant women as compared to literate women. Another study conducted by Gebremedhin et al. [8] also indicated that there is a positive association between anaemia and literacy status of women. Based on the above findings, it is possible to conclude that women who are formally educated are likely to be knowledgeable of the nutritional factors that predispose women to anaemia.

While most of the participants in the study were Muslims, a majority of them also indicated that they had diagnosed with anaemia (65\%). This was also mentioned by a majority of the Key Informants in the Key Informant Interviews. Since almost all the Somali community are Muslims, some cultural beliefs are erroneously attributed to religious restrictions. This finding, therefore, shows a trend that "Islamic religious" affiliation tends encourages lifestyles that predispose mothers to anaemia as compared to the Christian faith. This finding could be explained by the dietary restrictions of culture, wrongly attributed to religion by the participants.

The study finds that mothers who had less than three pregnancies tended to be negative for anaemia while those with more than three children tended to be positive for anaemia. Similarly, mothers who had had three and below number of live births also tended to be negative for anaemia. 
Higher gravidity increased the likelihood of anaemia conversely. Higher prevalence of anaemia among women with higher gravidity may be due to limited resource and larger family size. In a study conducted by [9] the parity and gravidity had a clear effect on the prevalence of anaemia, the women with more than two pregnancies had a significantly higher rate of anaemia. This might be due to the increase in women's nutritional needs during pregnancy.

\section{Socio-Cultural factors associated with the anaemia}

Socio-cultural factors refer to the larger scale forces within cultures and societies that affect the thoughts, feelings and behaviours [10]. The study revealed that women who failed to take iron tablets during pregnancy also had anaemia. Such restrictions were linked to socio-economic factors. The study also affirmed dietary restrictions during pregnancy when respondents indicated that they changed their diets during pregnancy. Similarly, women who indicated that they were Muslims were also anaemia positive. According to Chakona, et al. [11] all societies have traditional and/ or religious beliefs regarding harmful and beneficial food and even food quantity for pregnant women. These cultural factors could have thus influenced nutrition and thus anaemia among women of reproductive age in the study area. This finding may lead to an understanding that socio-cultural factors promoting dietary restrictions and change during pregnancy influence anaemia.

Based on the above findings, it could be reasoned that existence dietary restrictions have a bearing in anaemia among pregnant women. A study conducted by Dwumfour-Asare, et al. [12] concluded that cultural factors are considered to be one of the inescapable causes of anaemia and that these cultural factors and or religious beliefs and practices in food restrictions deprive pregnant women of relevant dietary nutrition. A study conducted in India also revealed that major food considered as harmful to pregnancy include eggs, fish, meat, papaya, banana, eggplant, beans, peas etc [13]. Adherence to such beliefs and practices could be reinforced by the institutionalization of culture in society. It could also be inferred based on the emerging themes during the Key Informant interviews that men are the custodians of such cultures and traditions

\section{Recommendations}

Since the incidence of anaemia still prevalent among women attending antenatal clinic in Garissa County, there is a need for a concerted effort towards reduction of the causes of anaemia in the County. This could be done through the local partners (NGOs and CBOs).

The demographic factors found to be associated with anaemia include parity, education and religion. This study, therefore, recommends that special education campaigns on the nutritional requirements and the benefits of iron supplements issued at the health facilities targeting this group need to be developed as a matter of priority. Such kind of education should also be integrated in religion [14-17].

Economically, there should be deliberate efforts made towards women empowerment by enhancing their autonomy within the family, through the facilitation of their ability to earn and participate in resource allocation and distribution by the county government. This could be done through enactment of economic policies targeting the women. When this is achieved, women will be able to participate in their own health promotion practices and thereby complimenting the provision of education as mentioned above.

The study revealed that most of the factors assessed had significant associations with the outcome variable of anaemia. For future research, the study recommends that the magnitude of the contribution of the various factors to the outcome variable being investigated. The direction of the relationship between the various factors and the outcome variable also to be investigated for this community. Also, the study revealed the existence of dietary prescriptions and proscriptions among pregnant women in the study area. Future studies could investigate positive prescriptions and proscriptions as practised in the study area so as to come up with recommendations on how to leverage such to promote nutrition among pregnant women in the study area [18-20].

The study was concerned prevalence of anaemia among women of reproductive age attending antenatal clinic in Garissa county referral hospital. The population for this study comprising of pregnant women who are between 18-49 years of ages attending antenatal clinic in Garissa County Referral Hospital were recruited. The study targeted women who were going for ANC services at the health facility during the clinic days. The results of this study are limited only to the data from the results of the questionnaire and interviews that were conducted by the investigator. The findings and conclusions made out of this study apply to the area of study and cannot be generalized for the whole of Country

\section{References}

1. Perez Y, Presti K, Eden AN, et al. (2019). Iron-Deficiency Anaemia During Childhood. In Anaemia in the Young and Old. Springer, Cham. pp. 81-93

2. Speed MS, Azeez MJA (2019) Determinants of anemia among pregnant women.

3. World Wide Prevalence of anaemia (2018) WHO Global Database on Anaemia.

4. Higgins JM (2018) US. Patent No. 9,938,557. Washington, DC: U.S. Patent and Trademark Office.

5. Furness D (2018) Vitamin and mineral supplements: Maternal diet and nutrient requirements in pregnancy and lactation. AJP. 99(1177). pp. 76.

6. Garissa Provincial General Hospital (PGH) | Ehealth Kenya'. N.p., 2015.

7. World Wide Prevalence of anaemia (2018) WHO Global Database on Anaemia.

8. Gebremedhin S, Enquselassie F (2011) Correlates of anaemia among women of reproductive age in Ethiopia: Evidence from Ethiopian DHS 2005. Ethio J Health Develop. 25(1). pp. 22-30.

9. Guralnik JM, Eisenstaedt RS, Ferrucci L, et al. (2004) Prevalence of anaemia in persons 65 years and older in the United States: evidence for a high rate of unexplained anaemia. Blood. 104(8). pp. 2263-2268.

10. Stehr N (2017) Knowledge societies. In society and knowledge.routledge. pp. 299-322.

11. Chakona G, Shackleton C (2019) Food Taboos and Cultural Beliefs Influence Food Choice and Dietary Preferences among Pregnant Women in the Eastern Cape, South Africa. Nutrients, 
11(11), pp. 2668.

12. Dwumfour-Asare, B, Kwapong MA (2013) Anaemia awareness, beliefs and practices among pregnant women: A baseline assessment at Brosankro community in Ghana. J Natur Sci Res, 3(15). pp. 1-9.

13. Hari V (2019) Plant foods for nutritional good health. Notion Press.

14. Abdi, SI (2013) Factors contributing to anaemia among antenatal mothers in Garissa County: A case study of Garissa Provincial Hospital.

15. Bivolarska AV, Gatseva PD, Maneva, Al (2016) The role of eating habits on the iron status of pregnant women. J Amer Coll Nutr 35(2). pp. 118-124.
16. Esen UI (2017) Iron deficiency anaemia in pregnancy: The role of parenteral iron. J Obst Gynaecol. 37(1). pp. 15-18.

17. Singal N, Setia G, Taneja BK, et al. (2018) Factors associated with maternal anaemia among pregnant women in rural India. Bangl J Med Sci. 17(4). 583-592.

18. Republic of Kenya; national guidelines for the diagnosis, treatment and prevention of malaria in Kenya (2010) Ministry of public health and sanitation.

19.https://www. myaccountingcourse.com/accountingdictionary/economic-factors

20. World Health Organization. (2001). Iron deficiency anaemia: assessment, prevention and control A guide for programme managers. 